\title{
Using Stereoscopic 3D Images for Effective Learning in Primary School
}

\author{
Dede Permana, $\mathrm{a}^{*}$ \\ ${ }^{1}$ Department of Primary Teachers Education, Nusa Putra University, Sukabumi, 24355, Indonesia \\ adede.permana@nusaputra.ac.id \\ ${ }^{*}$ Corresponding Author \\ Whatsapp Number [+6285333566610]
}

How to Cite : Permana, D. (2019). Using Stereoscopic 3D Images for Effective Learning in Primary School. International Journal for Educational and Vocational Studies, 1 (5), $411-415$

\section{ARTICLE HISTORY}

Received: 11 July 2019

Revised: 20 August 2019

Accepted: 6 September 2019

\section{KEYWORDS}

Stereoscopic 3D Images,

Effective Learning,

Primary School

\section{ABSTRACT}

This study aims to determine the effect of using stereoscopic 3D image on learning effectiveness This research was conducted through a quasi-experiment in primary schools by using control class and experimental class. This research was joined by 52 participants ( 26 students in control class and 26 students in experimental class). The research conclusions indicate that, 1) stereoscopic 3D images can be used through integration into textbooks as illustrations increasing the primary school students' perception about classroom activities (i.e., motivation, interest, challenge and excitement). and 2) textbooks integrated with stereoscopic 3D images are proven effective in improving the students' concept mastery, as seen from the independent sample t-test by using SPSS resulting in a probability $(p)$ value of 0.000 with a significance level of 0.05 so that $p<0,05$.

This is an open access article under the CC-BY-SA license.

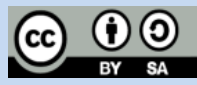

\section{INTRODUCTION}

Effective learning is a process that helps students to understand easily, pleasantly, and can achieve learning goals. In the implementation of effective learning in primary school, one of the signs that must be considered is that the learning process should be tailored to the uniqueness of the concept/subject and the development of primary school students' thinking. Adjustments can be done in various ways, one of them is by using $3 \mathrm{D}$ images in learning.

In addition, Syarifuddin, Syahrial, \& Suparman (2017:54) Revealed that one method of learning is direct experience in the field. However, not every school can implement the method, because it is limited to the existing permissions and programs. By using of stereoscopic 3D images technology for learning are expected to take on the real world without having to take them out of the class. A proverb says that a picture is worth a thousand words. Images are visual tools that are able to present something more concretely and realistically. Illustrations will make the abstract concept more memorable, explain the details of the text, and make it easier for students to understand.

Laitinen (2014:22) states that a visual illustration aims to create a more complex understanding of ideas and structures that are present in the text. Shibata (2017:16) explains that learning materials presented with the help of 3D images will help students focus on specific details. The material with $3 \mathrm{D}$ images also brings students to come up with new questions. From some of these opinions, it can be concluded that the illustration will help students achieve optimal learning that is able to develop their abilities based on the planned learning objectives.

Integrating images into textbooks will make it easier for students to master the concept of learning. Eitel et al (2013:63) reveal that the integration of text and images in learning will provide benefits for students to understand the learning materials. Lenzner, Schnotz, \& Müller (2013:811) reveal that the image affects the mood of learners in understanding materials since if a textbook is accompanied by an interesting picture, it will increase students' interest to learn, so that effective learning can be achieved. Currently, Stereoscopic 3D images are still rarely used for learning applications. The utilization of Stereoscopic 3D image medium is still limited to aspects of entertainment, such as children's story books, coloring books, and three-dimensional posters.

Ferdig R, Blank J, Kratcoski A, and Clements R (2015) reveal that three-dimensional (3D) stereoscopic can effectively be used to engage students with a complex disciplinary content as presented with informative representations of abstract concepts. Besides, stereoscopic 3D images can enhance learning and retention in some educational materials, especially the concept of science. In stereoscopic images, phenomena of science are presented in three dimensions so as to look like in real life and thus, it 
allows the user to be able to understand the concepts of making the main connection between structure and function.

Englund (2010:7) reveals that the working principle of stereoscopy is to make every eye see the image of its own landscape, ss in the real world. When looking at the real world, the eye sees two slightly different images in which images for each eye are different so that the brain can feel the depth of the image. In line with some opinions above, Banks MS, Read JC, Allison RS, \& Watt SJ (2012) reveals that the working principle of Stereoscopic 3D images is dependent on binocular vision. Binocular vision is a vision that occurs when both eyes are used together. The binocular vision system relies on the fact that two eyeballs are apart about 2 inches $(5 \mathrm{~cm})$ and therefore, each eye will see the world from a slightly different perspective, and the binocular vision system in our brain has the ability to correlate objects seen in two eyes even though they are seen slightly differently.

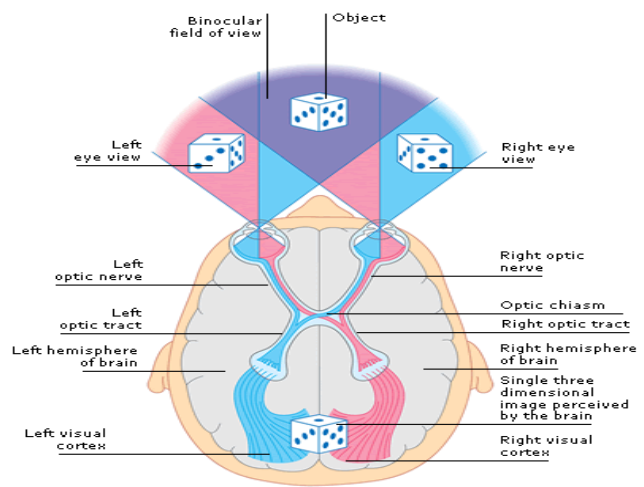

Fig. 1 Process of Binocular Vision

Stereoscopic 3D images technology can only be viewed by using the tool of three-dimensional (3D) glasses. Usually, most used glasses are colored with red and cyan lenses. The working principle of the 3D glasses is as in figure 3 . first the red lens will filter the blue color so that the color will not penetrate the red lens and it will look blue like a black line. While, the red color will pass in the red lens filter and look as red line. At the same time, the white light from the background and on the red filter will appear as a red line so that the original red color will blend in the background.10 and thus, the red lens will only recognize the blue color, and the blue lens will only recognize the red color.

Joseph (2011) reveals that three-dimensional (3D) visualization becomes very useful. $3 \mathrm{D}$ visualization educational tools tend to be most useful when demonstrating concepts that can't be encountered. Stereo visualization allows students to get used to and view from a world that is difficult or impossible to experience in the real life. As a proverb says that a picture is worth a thousand words. Therefore, the insertion of Stereoscopic 3D images in textbooks is used for the illustration of learning materials so that students will receive the learning materials completely. In addition, the development of stereoscopic 3D-based textbooks will also contribute to the importance of visual literacy in working and understanding science. If it happens, it will help teachers and students to make learning science more valuable and meaningful. Stereoscopic 3D images technology in textbooks is conducted by inserting stereoscopic 3D images into students' scientific activity sheets and learning materials in textbooks. Thus, the stereoscopic 3D image is expected to function as a medium to carry out observation activities and as a medium to provide illustrations of learning materials in textbooks. In practice, students will use the 3D glasses that have been provided to be able to see the three-dimensional (3D) effect on the picture. One of the examples of such integration is as Fig 3.

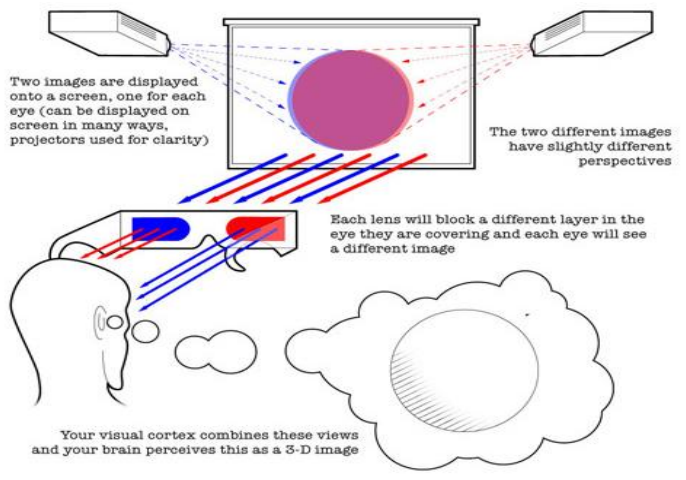

Fig. 2 The working principle of Stereoscopic 3D glasses
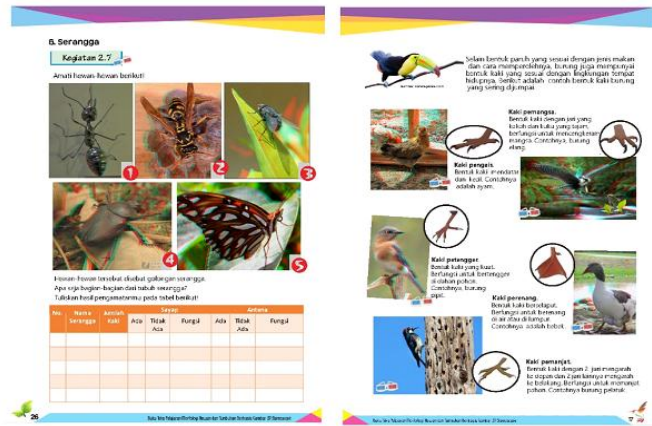

Fig. 3 Examples of Integrating 3D Stereoscopic Images in the Textbook

In figure 4 show that the integration of stereoscopic 3D images in textbooks is to carry out the observation activities of animal body shape and function. Through the integration, students are invited to carry out observation activities by observing stereoscopic $3 \mathrm{D}$ images and then filling in a few questions on the observation sheet.
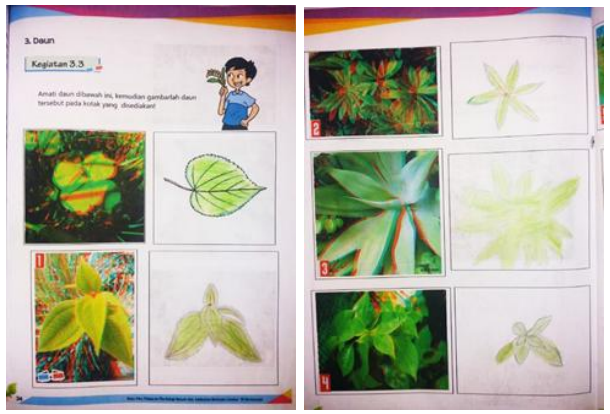

Fig. 4 Examples of observation Activities in textbook with a Stereoscopic 3D images 
Figure 5 is another example of using stereoscopic 3D images for observation activities. Pictures of different types of leaves by image processing stereoscopic $3 \mathrm{D}$ is created as an object of observation. From the integration of stereoscopic 3D images, students are directed to view and study leaf forms through observation of stereoscopic $3 \mathrm{D}$ images of various leaf forms. Afterwards, students are asked to describe the shape of the leaf in the provided column.

\section{METHODS}

This research aims to determine the impact of the using stereoscopic 3D images technology into textbooks on the learning process. The used research design is a quasi-experiment conducted on fourth-grade students in two primary schools with similar characteristics. One school as an experimental class, the other one as an control class. A total of 52 students participated in this research in which 26 students were in the experimental class and 26 students were in the control class. In the control class, students followed the learning by using conventional textbooks that they usually used on a daily basis. Meanwhile in the experimental class, students learned to use textbooks that had been integrated with stereoscopic 3D images technology.
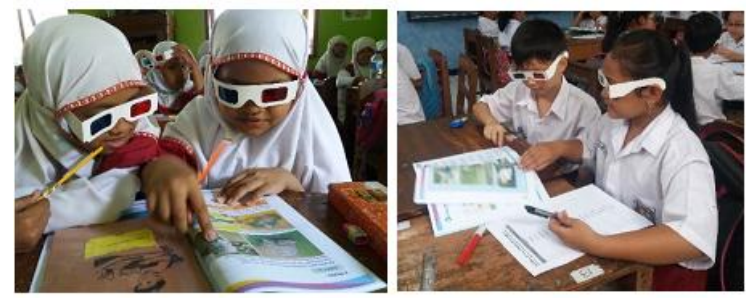

Fig. 5 Learning Proccess using textbooks that have integrated stereoscopic 3D images

The data collection technique was conducted by giving pre-test and post-test to the students in both classes. The tests were conducted to measure the mastery of concepts before and after their learning by using textbooks. To find out the impact of integrating stereoscopic 3D images into textbooks on learning, it could be seen from the results of students' conceptualization tests by using textbooks integrated with stereoscopic 3D images and students' using ordinary textbooks.

\section{RESULTS AND DISCUSSION}

The mastery of Natural Sciences concept in both classes has an improvement if it seen from the increase of the average value of students' pre-test and post-test. It is shown in the following table 1.
Table 1. Comparison of Average Score of Experimental Class and Control Class

\begin{tabular}{lccc}
\hline \multirow{2}{*}{ Class } & \multicolumn{2}{c}{ Average Score } & \multirow{2}{*}{ Improvement } \\
\cline { 2 - 3 } & Pre-test & Post-Test & \\
\hline Experimental & 46.88 & 79.62 & $69.8 \%$ \\
\hline Control & 45.50 & 62.31 & $36.9 \%$ \\
\hline
\end{tabular}

Based on the data, it can be seen that the average of the given pre-test value before the students learn to use the developed product is 46.88. Meanwhile, the given average post-test value after the learning is 79.62 . In the control class, the average initial value of mastering the concept of Natural Sciences students is 45.50. After the learning, post-test is given to the students and the result of the average mastery of Natural Sciences students' concept increase to 62.31. Based on the pre-test and post-test data, it can be seen that learning by using textbooks of animal morphology and plant based on stereoscopic 3D images can give result of concept mastery of Natural Sciences that is higher than learning by only using conventional textbooks.

The age of primary school children is a time that children still like pictorial things. According to Ganea et al (2011:1421) the exposure of the picture on the book for children will frame the book into a vast window of the world. This research finds that integration of stereoscopic 3D images into textbooks in primary school can be conducted. Books that have been integrated with stereoscopic 3D images can help students focus on learning so that learning goals can be achieved. Based on the analysis results of concept mastery in both classes (control and experimental), it is known that in both classes, there is an increase in terms of concept mastery. However, the concept mastery in the experimental class tends to increase higher than one in the control class. Molnar and Benedek (2015:2669) revealed that by extending 2D representations to three-dimensional ones, pictorial contents become more lifelike, getting closer to practice, creating the basis for a new view of pictorial thinking, giving rise to the emergence to a very effective method of dealing with information overload. According to Zhetipisbayeva, B.A. Shelestova, T.Y., Kazimova, D.A. (2017:162) mention that illustrations in textbooks play a role in the perception of primary school students and affect classroom activities including motivation, interests, challenges and fun. Meanwhile, Price (2015) reveals that stereoscopic medium has the potential to benefit learning. The use of stereoscopic is to make something become unique. This medium can accommodate specific requirements for understanding topics and tasks with object visualization and complex phenomena where the depth of the image is tight to convey core ideas. The presentation of drawings in textbooks serves as a medium of illustrator that will assist students in constructing an understanding of abstract material concepts. If they are not assisted with the presentation of 3D images, it is feared that the material concept becomes abstract. In fact, the age of primary school students is in the age range of 7-11 years meaning that they are still in the stage of concrete operational thinking. According to Piaget in Ghazi and Ullah (2016:79), children in the concrete operational stage 
still cannot think either logically or abstractly. Children's way of thinking is limited to concrete, real and definite things.

The use of integrated textbooks of stereoscopic 3D images has been shown to increase the mastery of students' concepts of learning materials. It means that through integrated textbooks integrated with stereoscopic 3D images, students can help discover the meaning of learning activities. Meaningful learning experiences will influence students' view of science. According to Hacieminoğlu et al (2014: 1), the factors related to students' view of science include the degree of education, student achievement and meaningful learning. If students have a good view of science, the education goal has been achieved well.

\section{CONCLUSION}

Stereoscopic 3D images technology will serve as an illustrator of great interest to students and can provide an enjoyable experience for students in their effort to understand the learning concept. Stereoscopic 3D images technology can provide a realistic experience of observation activities without having to search for the real object. It will make it easier for students to learn objects that are difficult to encounter in the school environment. Besides, giving illustrations of learning materials by using stereoscopic 3D images is ideally used in textbooks because of the characteristics of primary school students who still need concrete things to understand the materials. Based on the experimental results, it is found that indirectly, the integration of stereoscopic 3D images technology has a positive impact on the students' level of concept mastery when compared to the use of regular textbooks.

\section{REFERENCES}

Ardenghi, L, Pozer,. \& Roth, Wolff Michael. (2015). Understanding Visuals in Science Textbooks. In Tobin, Kenneth (Eds.), A Handbook: Teaching and Learning Science. (hlm.106-114) New York: Praeger Publishing.

Banks MS, Read JC, Allison RS, Watt SJ. (2012) Stereoscopy and the human visual system. SMPTE motion imaging journal. 121(4), 24-43. doi: $10.5594 / \mathrm{j} 18173$.

Eitel, Alexander., Scheiter, Katharina., Schüler, Anne., Nyström, Marcus., \& Holmqvist, Kenneth. (2013). How a picture facilitates the process of learning from text: Evidence for scaffolding. Learning and Instruction. 28, 48-63. doi: 10.1016/j.learninstruc.2013.05.002.

Englund. Rickard. (2010). Rendering Methods for 3D Fractals. (Unpublished master's thesis). Retrieved from http://diva-portal.org/smash/record.jsf?pid=diva 2:32556

Ferdig, R., Blank, J., Kratcoski, A., \& Clements, R. (2015). Using stereoscopy to teach complex biological concepts. Advances in physiology education, 39(3), 205-208. doi: 10.1152/advan.00034.2014.

Ganea, P. A., Ma, L. and DeLoache, J. S. (2011), Young Children's Learning and Transfer of Biological Information From Picture Books to Real Animals. Child Development, 82, 1421-1433. doi:10.1111/j.1467-8624.2011.01612.x.

Ghazi, Safdar, R., \& Ullah, Karim. (2015) Concrete Operetional Stage of Piaget's Cognitive Development Theory: An Impication In Learning General Science. Gomal University Journal of Research (GUJR). 31 (1). 78-89.

Hacıeminoğlua, Esme., Ertepınarb, Hamide,. Yılmaz-Tüzünc, Özgul,. \& Çakırd, Hasan. (2014) Students and school characteristics related to elementary school students' views of the nature of science. International Journal of Primary, Elementary and Early Years Education. 3(13), 1-22. doi: 10.1080/03004279.2013.865655.

Joseph, Norman. (2011). Stereoscopic Visualization as a Tool for Teaching Astronomy Concepts. (Unpublished master's thesis). Retrieved from https://www.learntechlib.org/p/128483.

Laitinen, Mikko. (2014). Thousands of words. A comparative study on the functions of pictorial illustrations in English language textbooks. (Unpublished master's thesis). Retrieved from https://jyx.jyu.fi/dspace/handle/123456789/4312 1 .

Lenzner, A., Schnotz, W., \& Müller, A. (2013). The role of decorative pictures in learning. Instructional Science. 41(5), 811-831. doi: 10.1007/s11251-012-9256-z.

Molnár, A, György., \& Benedek, András. (2015) Three Dimensional Applications in Teaching and Learning Processes. Social and Behavioral Sciences. 191. 2667-2673. doi: 10.1016/j.sbspro.2015.04.600.

Northam, Lesley., Asente, Paul., \& Kaplan, C.S. (2013). Stereoscopic 3D Image Stylization. Computers \& Graphics. 37(5). 389-402. doi: 10.1016/j.cag.2012.11.005.

Price, C, Aaron., \& Lee, Hee-Sun., D. Plummer, Julia., SubbaRao, Mark \& Wyatt, Ryan. (2015). Position Paper On Use Of Stereoscopy To Support Science Learning: Ten Years Of Research. Journal of Astronomy \& Earth Sciences Education (JAESE). 2 (1), 17-26. doi: 10.19030/jaese.v2i1.9278. 
Shelestova, T., Zhetpisbayeva, B., \& Kazimova, D. (2017). The effect of illustrations and simulations in English course books in a Kazakhstani context on primary school students' English language achievement. International Electronic Journal Of Elementary Education. 10(1), 163-174. doi: 10.26822/iejee.2017131946.

Shibata, Takashi., Ishihara, Yoshiki., Sato, Kazonuri., Ikejiri, Ryohei. (2017) Utilization of Stereoscopic 3D Images in Elementary School Social Studies Classes. Proceedings of Electronic Imaging/Stereoscopic Displays and Applications XXVIII, Society for Imaging Science and Technology, California, USA. pp. 167-172.

doi: 10.2352/ISSN.2470-1173.2017.5.SDA-372.

Syarifuddin,. Syahrial, Z,. Suparman, A. (2017). Virtual Museum: A Learning Material of Indonesia National History. International Journal of Multicultural and Multireligious Understanding (IJMMU). 4(6), 51-60. doi: 10.18415/ijmmu.v4i6.9 